\title{
Cellular Automata Based Modeling for Evaluating Different Bus Stop Designs in China
}

\author{
Haoyang Ding, ${ }^{1,2}$ Wei Wang, ${ }^{1,2}$ Tianming Luo,, ${ }^{1,2}$ Zhen Yang, ${ }^{1,2}$ Ye $\mathrm{Li}^{1,2}$ and Zhibin $\mathrm{Li}^{1,2}$ \\ ${ }^{1}$ Jiangsu Key Laboratory of Urban ITS, Southeast University, Nanjing 210096, China \\ ${ }^{2}$ Jiangsu Province Collaborative Innovation Center of Modern Urban Traffic Technologies, Nanjing 210096, China \\ Correspondence should be addressed to Haoyang Ding; dinghy123@hotmail.com
}

Received 24 October 2014; Accepted 31 January 2015

Academic Editor: Tetsuji Tokihiro

Copyright (c) 2015 Haoyang Ding et al. This is an open access article distributed under the Creative Commons Attribution License, which permits unrestricted use, distribution, and reproduction in any medium, provided the original work is properly cited.

\begin{abstract}
A cellular automaton model is proposed to simulate mixed traffic flow composed of motor vehicles and bicycles near bus stops. Three typical types of bus stops which are common in China are considered in the model, including two types of curbside bus stops and one type of bus bay stops. Passenger transport capacity of three types of bus stops, which is applied to evaluate the bus stop design, is calculated based on the corresponding traffic flow rate. According to the simulation results, the flow rates of both motor vehicles and bicycles exhibit phase transition from free flow to the saturation one at the critical point. The results also show that the larger the interaction between motor vehicle and bicycle flow is near curbside bus stops, the more the value of saturated flows drops. Curbside bus stops are more suitable when the conflicts between two flows are small and the inflow rate of motor vehicles is low. On the contrary, bus bay stops should be applied due to their ability to reduce traffic conflicts. Findings of this study can provide useful suggestions on bus stop selection considering different inflow rate of motor vehicles and bicycles simultaneously.
\end{abstract}

\section{Introduction}

Bus travel is becoming increasingly popular in the world since it is more environmentally friendly than traveling by car. Many researchers have found that the bus stop, which serves as a crucial part in the bus system, always has great effect on traffic flow near the bus stop. In developed countries, such effect often occurs under the condition of homogeneous traffic flow, since in these countries motorized vehicles are dominant in traffic compositions [1]. However, bicycles are still prevalent in daily short-distance trips in developing countries $[2,3]$. In some cities of China, for instance, the bicycle share of trips usually varies from $20 \%$ to $50 \%$ [4]. Therefore, when studying the impact of bus stops on traffic flow in developing countries, the traffic compositions condition should be set as a heterogeneous traffic flow where both motorized vehicles and bicycles are considered.

The conflict between buses and bicycles is not prominent on urban arterial roads where vehicle flow and bicycle flow are well separated by physical segregation. However, as a complement to the urban mass transit, most bus routes are laid out on the secondary roads which are usually made up of one motor lane and one bicycle lane in each direction. Typically, there are three types of bus stops on secondary roads in China: curbside stops without physical segregation, curbside stops with physical segregation, and bus bays, as shown in Figure 1. In Figure 1, Type I is curbside stops. These bus stops are set on the sidewalk. So buses have to pull over to the curb and occupy the bicycle lane to dwell and there is no physical segregation between the motor lanes and the bicycle lanes. Type II is similar to Type I, and the only difference is that bicycle lanes are physically separated from motor lanes except the segments at the bus stops to regulate the traffic behavior of cyclists and bus drivers. Type III is baystyle stops which are set on the separation strips. The bicycle lanes are physically separated from motor lanes, and buses do not occupy any lanes to dwell. Up to now, few insightful researches have been conducted on the regulation of selecting bus stops types in terms of traffic flow characteristics. It is very common that a certain kind of bus stop is selected without taking the effects of various traffic flow characteristics into consideration in China currently.

The primary objective of this study is to develop a cellular automaton (CA) model based on the three specific types of 


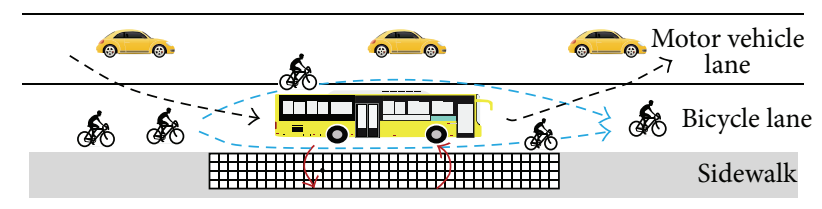

(a) Type I

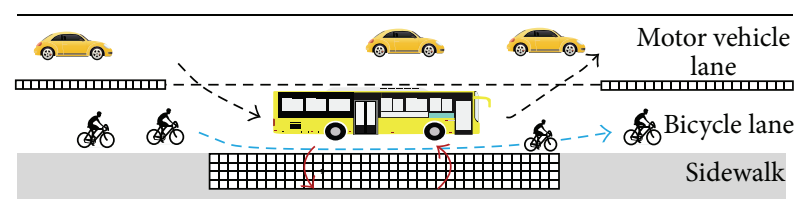

(b) Type II

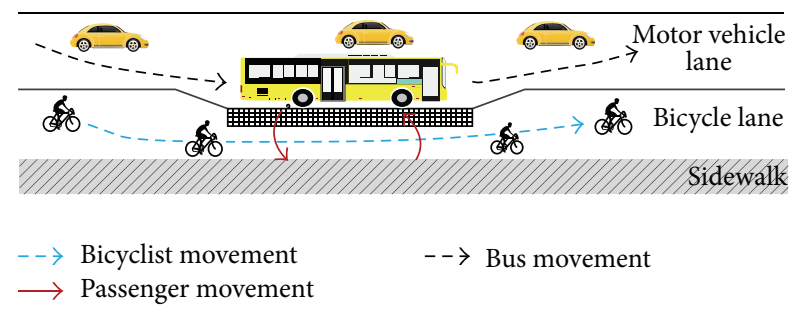

(c) Type III

FIGURE 1: Three types of bus stops on secondary roads in China.

bus stops, which can reflect traffic features in a mixed traffic flow composed of motorized vehicles and bicycles near bus stops. The remaining parts of the paper are organized as follows: previous literatures are reviewed in the next section. Section 3 introduces the cellular automaton (CA) model used in this study. Then, simulation results and findings are discussed in Section 4. The conclusions and analyses are summarized in the last section of the paper.

\section{Literature Review}

To uncover the traffic nature and understand the behavior of the traffic flow, traffic problems have been studied by physicists for more than 50 years and various modelling approaches have been proposed [5]. In general, they can be classified to two kinds: macroscopic and microscopic approaches. In macroscopic models, traffic is viewed as a compressible fluid formed by the vehicles but these individual vehicles do not appear explicitly in the theory [6]. In contrast, in microscopic models like gas-kinetic models [7-9], car-following models [10-12], and cellular automaton (CA) models [13], attention is focused on individual vehicles and each of them is represented by a "particle." The nature of the interaction among these particles is determined by the way the vehicles influence each other's movement. Therefore, microscopic models offer the possibility to study various fundamental aspects of traffic system.

Here we will focus on CA models. Time and state variables are discrete in CA models, which makes them ideally suited for computer simulations. In contrast to discretized continuum models, which is usually necessary for their numerical treatment, the discreteness is already taken into account in the definition of the CA model and its dynamics. This allows obtaining the desired behavior in a much simpler way [14]. CA models have been widely used for the description of traffic flow since Nagel and Schreckenberg proposed the well-known Nagel-Schreckenberg (NaSch) model in 1992 [15]. Although the NaSch model can reproduce some basic phenomena encountered in real traffic such as spontaneous jams, it cannot exhibit metastable states of high flow and synchronized traffic. Therefore, several improved NaSch models were proposed, such as the slow-to-start model $[16,17]$. In order to generalize the above idealized single-lane CA models to multilane traffic, lane-changing rules were developed and several attempts have been made so far in this direction [1821].

These CA models mentioned above are all concerned with motorized traffic. However, in developing countries like China, although there is a rapid increase in the usage of motorized vehicles, the effect of the considerable amount of bicycles on the traffic flow cannot be ignored. Therefore, several bicycle CA models were proposed to investigate the characteristics of bicycle flow [22-25].

It calls for further study if urban traffic including both motorized vehicles and bicycles is modeled using CA models and some researches on related topics have been done in recent years. Vasic and Ruskin presented a CA model for mixed traffic under the specific conditions of sparse bicycle flows and road sharing by two vehicle types, which could be found in many old European city centers [26]. A CA model considering the delay rules of bicycle through vehicle, the gap rules of vehicle through bicycle, and the disposal rules of the occupied conflict zone was proposed by Zhang et al. [27]. The characteristics of right-turning vehicles and straight-going bicycles at the intersection were analyzed using this model.

Since buses always have to temporarily occupy the bicycle lane to stop and pick up passengers in China and other developing countries, the bus stop is another place where the conflicts of vehicle flows and bicycle flows are very common. Zhao et al. provided a novel approach based on CA model to simulate the mixed flow near a curbside stop and discuss the influence of parameters such as stopped time of buses on traffic [28]. This model combined the so-called BCA model that is used to describe the behavior of nonmotorized vehicles and the NaSch model which is used in the description of motorized vehicles. However, there are still some deficiencies in this research. First, differences between various types of bus stops are not particularly considered. Only one type of bus stop is studied, so it cannot provide suggestions on bus stop selection. In addition, the model assumes that when buses dwell at stops, bicyclists would either wait behind the buses or change to the motor lane to pass the stopped buses. However, it is far from the real situation. Zhao et al. [29] found in their study that few bicyclists would like to wait behind the stopped bus even if it was difficult for them to pass it on the left. Nearly half of the bicyclists choose to pass the stopped bus from the right side through the gap between the curb and the bus. Moreover, the dwell time of the buses in this model is a constant value. However, Lu et al. [30] found that the dwell time could be affected by several factors near the bus stop. Based on our site observation, it is found that 


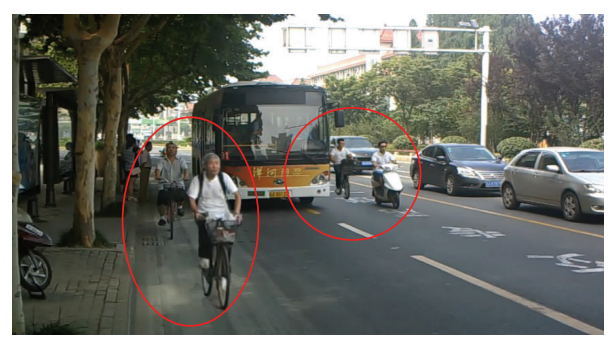

(a)

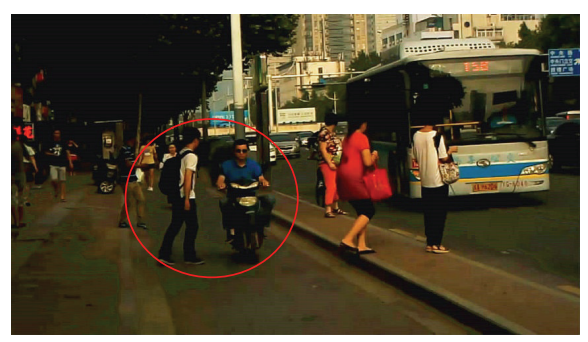

(b)

Figure 2: Traffic conflicts near the bus stop in China.
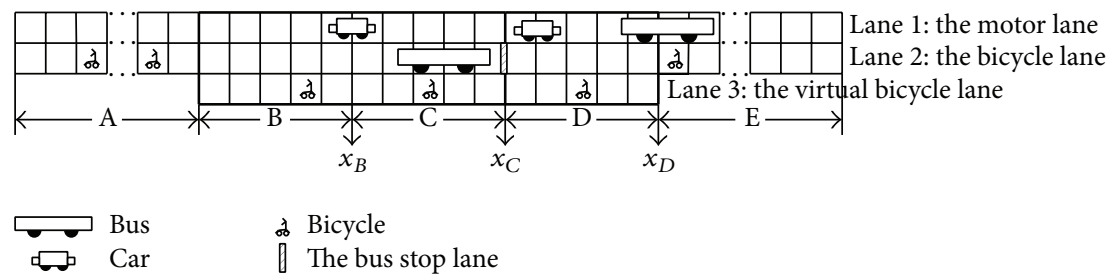

FIGURE 3: Sketch of the road in the mixed traffic system.

bicyclists who try to overtake the buses near curbside stops delay the boarding and alighting process. Then, it results in longer dwell time of buses (Figure 2(a)). As for bus bay stops, although bicycles are not affected by dwelling buses directly, passengers who need to approach or leave the bus stop have to cross the bicycle lane, which will inevitably slow down the traffic speed of bicycles and reduce the capacity of bicycle lane (Figure 2(b)).

In order to study the impact of different types of bus stops under various motor and nonmotor vehicle volumes, more realistic CA models are proposed in this study to evaluate the impact of three types of bus stops towards nearby traffic flow. Then, suggestions on bus stops selection are given based on the simulation results.

\section{Model}

In this paper, the typical Nagel-Schreckenberg cellular automaton model for motorized traffic flow and the Burgers cellular automaton model for bicycle flow are combined to simulate the mixed traffic flow near bus stops. Apart from these two models, the special lane-changing rules, which can reflect interactions between motor vehicles and bicycles, are also included in this section.

3.1. Introduction. A mixed traffic system consisting of a motor lane (called Lane 1) and a bicycle lane (called Lane 2) near the bus stop is investigated in this study, which is sketched in Figure 3. Each lane is divided into L cells with identical size.

The system contains two types of motor vehicles and one type of bicycles. The motor vehicles have cars with two-cell length and buses with four-cell length. The length of bicycle is one cell. The mixing probability $P_{\text {bus }}$ stands for the proportion of buses in motor vehicles. All buses must halt at the bus stop, and $T_{\text {dwell }}$ denotes the dwell time of the stopped buses at the stop. Only bicycles and buses near the bus stop are permitted to change lanes in the system.

In addition, this system is split into five sections, Sections $\mathrm{A}, \mathrm{B}, \mathrm{C}, \mathrm{D}$, and E. Section $\mathrm{A}$ is the entrance region and Section $\mathrm{E}$ is the exit region. Lane changing of bicycles and motor vehicles is not allowed in these two sections. A bus stop is located in Section C. Section B represents the upstream part and Section D represents the downstream part of the bus stop. For Type I and Type II bus stops, approaching buses can change to bicycle lane when they enter Section B to pull in the bus stops on bicycle lane in Section C. For Type III bus stops, buses are allowed to wait in Section B if there is a dwelling bus in Section C. The bus will pull out and change back to motor lane in Sections C or D.

As discussed above, a large proportion of bicyclists would like to pass the stopped bus through the gap between the curb and the bus in Types I and II. However, if the bicycle lane from Section B to Section D is occupied by buses in the CA model, no bicycle could "jump" across the buses. In order to take this situation into account, a virtual bicycle lane (called Lane 3) is added from the head of Section B to the end of Section $\mathrm{D}$ which is adjacent to the bicycle lane. The cells between Sections B and D in Lane 2 can only be used by buses, and all bicycles are not allowed to enter into this section. When a bicycle arrives at the head of Section A, it will move to the virtual bicycle lane if the end of the virtual bicycle lane in Section B is not filled with other bicycles. When it reaches the head of the virtual bicycle lane, it will change back to Lane 2, if possible.

3.2. Nagel-Schreckenberg Model. Nagel-Schreckenberg (NaSch) model is a famous model for m-vehicles, due to its capability of reproducing real traffic phenomena. In NaSch model, both space and time are discrete. The vehicles have 
integer velocity $v=0,1,2, \ldots, v_{\max }$. At each discrete time step $t \rightarrow t+1$, velocities and positions of vehicles are updated by the following rules [15]:

acceleration, $v_{j}(t+1 / 3) \rightarrow \min \left\{v_{j}(t)+1, v_{\max }^{m}\right\}$ deceleration, $v_{j}(t+2 / 3) \rightarrow \min \left\{v_{j}(t+1 / 3), d_{j}(t)\right\}$, randomization, $v_{j}(t+1) \rightarrow \max \left\{v_{j}(t+2 / 3)-1,0\right\}$, motion, $x_{j}(t+1) \rightarrow x_{j}(t)+v_{j}(t+1)$.

Here, $x_{j}(t)$ and $v_{j}(t)$ are position and velocity of vehicle $j$ in time step $t, d_{j}(t)$ is the number of empty cells ahead of vehicle $j . p$ is randomization probability, which is used to describe the different behavior patterns of the individual drivers. In our model, a NaSch model with $p=0.1$ is used in the following simulations.

It should be noted that, for the stopping bus $j$ at the bus stop, if its dwelling time $t_{\text {dwell }}(t)$ is less than $T_{\text {dwell }}$, then it continues to halt at the stop, and the dwelling time is updated as $t_{\text {dwell }}(t+1)=t_{\text {dwell }}(t)+1$. Otherwise, the bus becomes a pulling-out bus.

3.3. Burgers Cellular Automaton Model. Burgers cellular automaton (BCA) model can describe the flexibility of bicycles without considering complex lane-changing behaviors. In BCA model, each cell can be occupied by $M$ bicycles at most. The number of bicycles in each cell evolves as follows [25]:

$$
\begin{aligned}
U_{j}(t+1)= & U_{j}(t)-\min \left\{U_{j}(t), M-U_{j+1}(t)\right\} \\
& +\min \left\{U_{j-1}(t), M-U_{j}(t)\right\},
\end{aligned}
$$

where $U_{j}(t)$ represents the number of bicycles at cell $j$ at time step $t$. If cell $j+1$ in front of the current cell $j$ in Lane 1 is occupied by a motor vehicle at time step $t$, then $M-U_{j+1}(t)=$ 0 .

When applying BCA model to this study, we need to do some modifications to the model. In (1), the parameter $M$, which represents the maximum capacity of bicycle flow in each cell, is a constant value. However, in order to take the interactions of bicycles and buses into account, the value of $M$ is variable in our mixed traffic system. As a result, (1) is changed to

$$
\begin{aligned}
U_{j}(t+1)= & U_{j}(t)-\min \left\{U_{j}(t), M_{j+1}-U_{j+1}(t)\right\} \\
& +\min \left\{U_{j-1}(t), M_{j}-U_{j}(t)\right\} .
\end{aligned}
$$

In this modified equation, $M_{j+1}-U_{j+1}(t)$ represents the maximum number of bicycles that cell $j+1$ can accommodate and $M_{j}-U_{j}(t)$ represents the maximum number of bicycles that cell $j$ can accommodate.

For Type I and Type II bus stops, if the cell $i$ is in Sections $\mathrm{A}$ and $\mathrm{E}$, then $M=4$. If the cell $i$ is between the head of Section B and the end of Section D and is occupied by bus in Lane 2, then the value $M_{\text {occupied }}^{\text {Lane } 1}=M_{\text {occupied }}^{\text {Lane } 2}=1$ is applied to represent the maximum bicycle capacity of cell $i$ in Lane 3. Otherwise, $M=4$ is used in cell $i$. In addition, since the speed of bicycles is much lower when they try to pass the stopped bus from the right side through the gap between the curb and the bus than that of normal condition, the update rules of BCA should be modified. If the cell $i$ is in Section C and is occupied by a dwelling bus in Lane 2, cell $i$ in Lane 3 will be updated according to (2) only if this cell is not updated in the last time step. Otherwise, the bicycle in this cell cannot move forward during this time step. In this way, the speeds of bicycles at the bus stop reach $1.5 \mathrm{~m} / \mathrm{s}$ maximum.

For Type III bus stops, $M=4$ is used in Sections $\mathrm{A}$ and E. If the cell $i$ is between the head of Section B and the end of Section $\mathrm{D}$ and is occupied by a bus in Lane 2, then the value $M_{\text {occupied }}^{\text {Lane } 3}=2$ is applied to represent the maximum bicycle capacity of cell $i$ in Lane 3 . Otherwise, $M^{\prime}=3$ is used in cell $i$, which represents the situation that the bicycle lane is narrowed near the bus bay stops.

3.4. Lane-Changing Rules of Buses. Lane-changing rules of buses include the rules for approaching buses and pulling-out ones.

When approaching buses reach Section B in Lane 1, the drivers will change buses to Lane 2 if $C_{\text {available }}^{1}=1$. This equation means the four consecutive cells near the buses on destination lane are empty. Otherwise, if cells next to buses are occupied by dwelling buses or buses waiting for pullingin, buses will stay where they are and wait for enough empty cells.

A pulling-out bus would change from Lane 2 to Lane 1 in Section C or D if the following rules are fulfilled:

$$
\left(C_{\text {available }}^{1}=1\right), \quad\left(d_{i, \text { back }}>V_{\text {other }}\right) .
$$

Condition $C_{\text {available }}^{1}=1$ has the same meaning mentioned above and condition $d_{i \text {,back }}>V_{\text {other }}$ is the safety condition to avoid collision. $d_{i \text {,back }}$ represents the number of empty cells behind bus $i$ on the destination lane and $V_{\text {other }}$ represents the velocity of its following vehicle on the destination lane.

If a pulling-out bus could not successfully change to Lane 1 in Sections C and D, it will stop at the head of Section D in Lane 2 and wait for the satisfaction of lane-changing rules. Meanwhile, to avoid the endless waiting of pulling-out buses, the velocity of its following vehicle on the destination lane will be set to zero once there is a bus waiting at the head of Section D.

3.5. Lane-Changing Rules of Bicycles. In the conditions of Type II and Type III bus stops, bicycles can move forward only in Lane 3. However, bicycles can change from Lane 3 to Lane 1 (not passing through Lane 2) near Type I bus stops if they are hindered by stopped buses and road condition on Lane 1 is better than that on Lane 3. The rules are as follows:

$$
\begin{gathered}
\left(M_{i, \text { available }}^{\text {Lane } 1}>M_{i \text {,available }}^{\text {Lane } 3}\right), \quad\left(C_{\text {available }}^{2}=1\right), \\
\left(d_{\text {back }}>V_{\text {other }}\right) .
\end{gathered}
$$

$i$ represents the position of the studied bicycle among $\mathrm{L}$ cells. Condition $M_{i \text {,available }}^{\text {Lane } 1}>M_{i \text {,available }}^{\text {Lane } 3}$ means the capacity of cell $i$ in Lane 1 is larger than that in Lane 3. Condition $C_{\text {available }}^{2}=1$ means cell $i$ in Lane 1 is not fully filled. Condition $d_{\text {back }}>$ $V_{\text {other }}$ means safety condition is guaranteed. 
As long as bicycles overtake the lead bus stopped in Lane 2 , they will change back to Lane 3 immediately if cells in Lane 3 have enough space.

3.6. Boundary Conditions. The simulations are carried out under open boundary condition. In each time step, when the update of motor vehicles on the road is finished, we check the position of the last motor vehicle $x_{\text {last }}$ on the entrance of the motor lane. If $x_{\text {last }}>\max \left\{v_{\max }^{\text {car }}, v_{\max }^{\text {bus }}\right\}$, a motor vehicle is injected with the inflow rate $P_{\text {motor }}$. In this condition, if a random number rand $<P_{\text {bus }}$, the injected vehicle is a bus with velocity $v_{\max }^{\text {bus }}$ at the cell $\min \left\{v_{\max }^{\text {bus }}, x_{\text {last }}-v_{\max }^{\text {bus }}\right\}$. Otherwise, the injected vehicle is a car with velocity $v_{\max }^{\text {car }}$ at the cell $\min \left\{v_{\max }^{\mathrm{car}}, x_{\text {last }}-v_{\max }^{\mathrm{car}}\right\}$. On the bicycle lane, if the first cell is not fully filled with bicycles, new bicycles are inserted with the probability (inflow rate) $P_{\text {bike }}$ at the first cell. $M$ times of circulation will be done in each time step. The leading vehicles on each lane go out of the system at $\mathrm{L}$ and the following vehicle becomes the new leader.

\section{Simulation Results and Discussions}

In this section, the simulation settings of the CA model with respect to the three types of bus stops are explained in the first part. Then, the flow characteristics of motor vehicles and bicycles under different inflow rates $\left(P_{\text {motor }}\right.$ and $\left.P_{\text {bike }}\right)$ are illustrated in the three types of bus stops, respectively. A concept of passenger transport capacity is proposed to evaluate the performance of each type of bus stop under various mixed traffic flow situations in the last part.

4.1. Simulation Settings. In this section, the characteristics of mixed traffic flow near three types of bus stops are discussed in the traffic system mentioned earlier. The length of lane $L$ is set to 500 cells. Each cell corresponds to 3 meters, and each time step corresponds to 1 second. The mixing probability of buses in motor vehicles $P_{\text {bus }}$ is 0.15 . The maximum velocity of car and bus is 4 and 3, respectively. But if a bus is in Section $\mathrm{B}$ and Section $\mathrm{C}$, the maximum velocity is 2 since it needs to slow down to enter the bus stop. The first 10,000 time steps are discarded to avoid the transient behaviors. The flow rate is recorded by four virtual detectors on cells 50, 100, 150, and 200 and is obtained by averaging over 50,000 time steps and four detectors.

When bus stops are set on the sidewalk, bicyclists who try to overtake the buses near curbside stops delay the boarding and alighting process. Then, it results in longer dwell time of buses [30]. Based on our field observation, the average stop time of buses is about $20 \mathrm{~s}$ when there is little interference by bicycles. But it will increase to $30 \mathrm{~s}$ if a large number of bicycles pass through the bus stops during the dwelling time. An approximate linear relationship between dwelling time and occupancy rate of bicycle lane near the bus stop is obtained according to our field observation, so the dwell time of buses in Type I and II bus stops is calculated as follows:

$$
T_{\text {dwell }}^{\text {Type 1 }}=T_{\text {dwell }}^{\text {Type 2 }}=T_{\text {basic }}+10 \times \frac{\text { Num }_{\text {bike }}}{M \times L_{\text {B-D }}} .
$$

In (5), $T_{\text {basic }}$ is set to $20 \mathrm{~s}$. Num bike $_{\text {represents the number }}$ of bicycles from Section B to Section D when a bus stops in front of the parking line and $L_{\mathrm{B}-\mathrm{D}}$ represents the number of cells from Section B to Section D.

Because buses are free from the influence of bicycles in Type III bus stops, the dwell time in this condition is equal to $20 \mathrm{~s}$.

The object of the study is a bus stop with a single berth. The length of Sections A, B, C, D, and E in Type I is set to $L_{\mathrm{A}}=236, L_{\mathrm{B}}=12, L_{\mathrm{C}}=5, L_{\mathrm{D}}=12$, and $L_{\mathrm{E}}=235$ cells, respectively. In Types II and III, $L_{\mathrm{A}}=241, L_{\mathrm{B}}=7, L_{\mathrm{C}}=5$, $L_{\mathrm{D}}=7$, and $L_{\mathrm{E}}=240$ cells. The lengths of Sections B and D in Type I are longer than their counterparts in Types II and III. It is because near the bus stops in Type I there is no physical separation between motor vehicle and bicycle lines, which makes the conflict area between buses and bicycles larger.

4.2. Flow Characteristics and Phase Transition. The relationships between the flow and the inflow rates of both motor vehicles and bicycles in the proposed CA model are shown in Figures $4-6$. $q_{\text {motor }}$ and $q_{\text {bike }}$ represent the flow rate of the motor vehicles and the bicycles, respectively, and $P_{\text {motor }}$ and $P_{\text {bike }}$ represent the corresponding inflow rate. $q_{\text {motor }}$ is the average number of motor vehicles passing through the four virtual detectors in each time step. $q_{\text {bike }}$ is the average value that the number of bicycles passing through the four virtual detectors in each time step divided by $M$. When calculating $q_{\text {motor }}$ and $q_{\text {bike }}$, the first 10,000 time steps are discarded to avoid the transit behavior and the next 50,000 time steps are averaged.

Figure 4(a) shows the variation of the flow $q_{\text {motor }}$ with variable entering probability $P_{\text {motor }}$ in the case of some fixed value of $P_{\text {bike }}$ and in Figure $4(\mathrm{~b})$ the value of $P_{\text {bike }}$ is also variable. From the simulation results of Type I, it is found that, for a fixed $P_{\text {bike }}$, the flow rate of $q_{\text {motor }}$ increases with $P_{\text {motor }}$ first and then reaches the maximal value at a value of $P_{\text {motor }}$, which corresponds to the critical inflow rate $P_{\mathrm{mc}}$. And the maximal value of $P_{\text {motor }}$ is defined as its saturation inflow rate $q_{\mathrm{ms}}$ (which is pointed out in Figure 4(a) only for $P_{\text {bike }}=0$ ). Thus, the critical inflow rate $P_{\mathrm{mc}}$ of motor vehicles divides the flow into two regions, the free flow one and the saturated flow one.

(i) In the region of $P_{\text {motor }}<P_{\text {mc }}$, the flow of motor vehicles is free and $q_{\text {motor }}$ only increases with its own inflow rate $P_{\text {motor }}$. It is interesting to note that whatever the $P_{\text {bike }}$ is, the values of $q_{\text {motor }}$ have almost the same growth rates.

(ii) In the region of $P_{\text {motor }}>P_{\mathrm{mc}}$, the flow of motor vehicles reaches its saturation inflow $q_{\mathrm{ms}}$ and is independent of its own rate $P_{\text {motor }}$. However, with the increase of $P_{\text {bike }}$, both the saturated flow value $q_{\mathrm{ms}}$ and the critical value $P_{\mathrm{mc}}$ reduce until they reach a minimum. The value $q_{\mathrm{ms}}$ and the value $P_{\mathrm{mc}}$ decline from 0.31 and 0.45 at $P_{\text {bike }}=0$ to 0.14 and 0.2 at $P_{\text {bike }}=$ 0.28 . The drop ratios of $q_{\mathrm{ms}}$ and $P_{\mathrm{mc}}$ are about 55 percent and 56 percent. This suggests that the mixture of the motor vehicles and bicycles has a huge negative effect on the saturated flow rate of motor vehicle flow. 


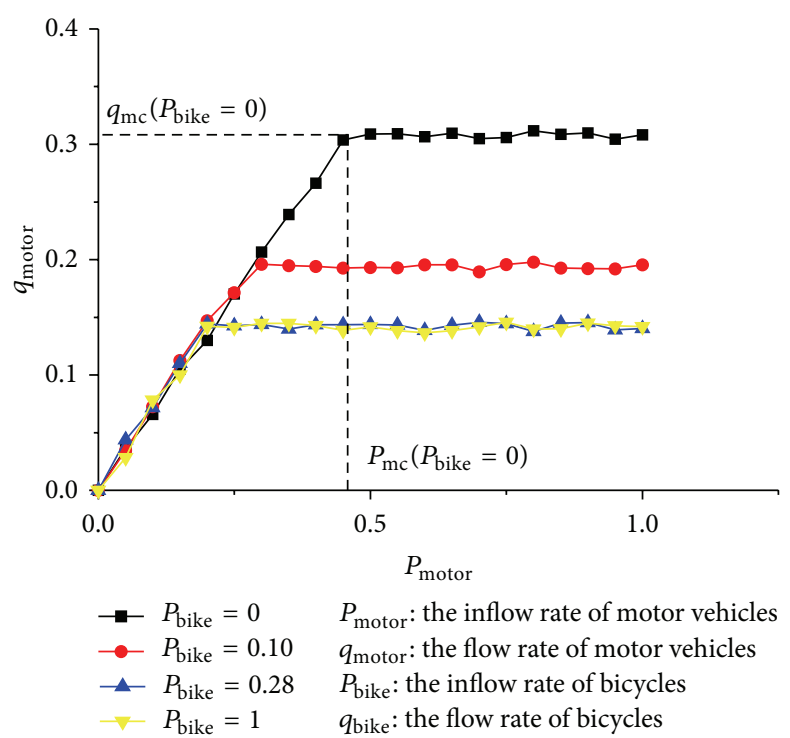

(a)

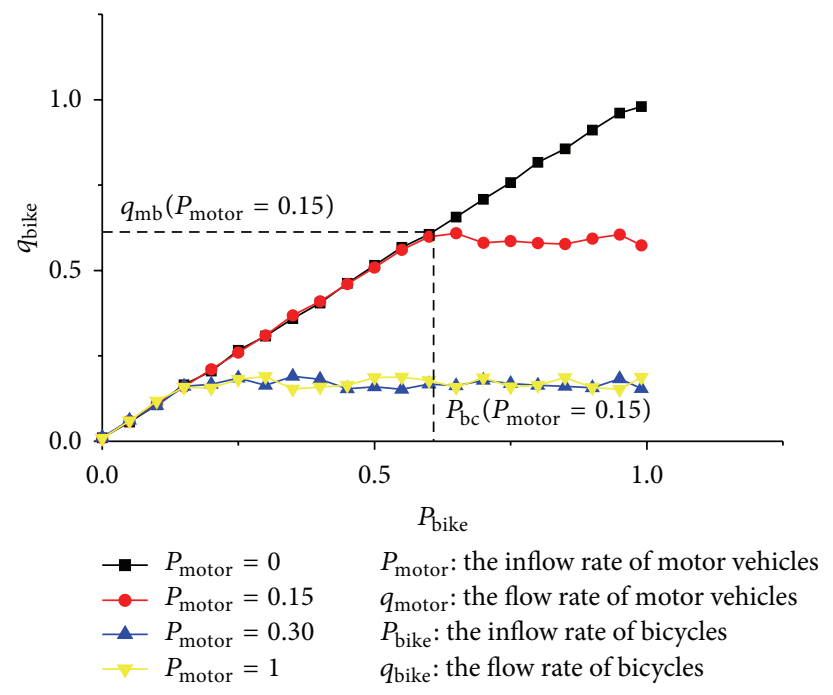

(c)

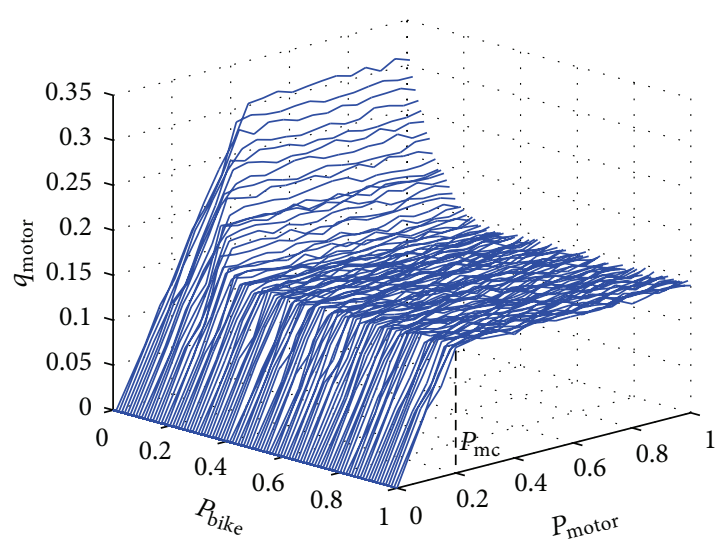

$P_{\text {motor }}$ : the inflow rate of motor vehicles $q_{\text {motor }}$ : the flow rate of motor vehicles $P_{\text {bike }}$ : the inflow rate of bicycles $q_{\text {bike }}$ : the flow rate of bicycles

(b)

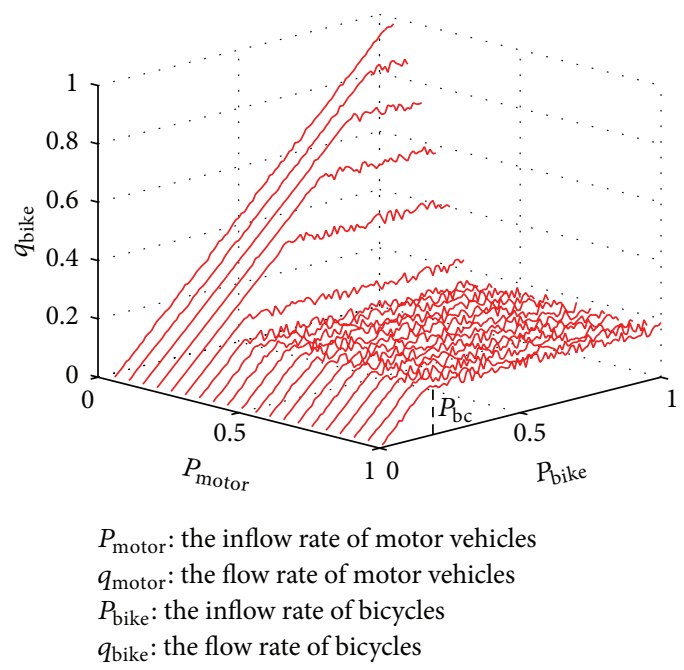

(d)

FIGURE 4: The simulation results of Type I bus stops.

Figure 4(c) shows the variation of the flow $q_{\text {bike }}$ with variable entering probability $P_{\text {bike }}$ in the case of some fixed value of $P_{\text {motor }}$ and in Figure $4(\mathrm{~d})$ the value of $P_{\text {motor }}$ is also variable. Traffic characteristics in the flow of bicycles are similar with those in the flow of motor vehicles described above. The critical inflow rate $P_{\mathrm{bc}}$ (which is pointed out in Figure $4(\mathrm{c})$ only for $P_{\text {motor }}=0.15$ ) of bicycles can also be found in the figures and it divides the flow into the free flow and the saturated flow as well. The only difference is that when there is no motor vehicle in the traffic system $\left(P_{\text {motor }}=0\right)$, bicycles can move forward freely without the interaction with cars and buses. As a result, the critical inflow rate $P_{\mathrm{bc}}$ does not exist when $P_{\text {motor }}=0$ and the maximal value of $q_{\text {bike }}$ reaches 1 when $P_{\text {bike }}=1$ in this condition. But besides that, the flow of bicycles is free and $q_{\text {bike }}$ only depends on its own inflow rate $P_{\text {bike }}$ in the region of $P_{\text {bike }}<P_{\mathrm{bc}}$. When the traffic flow lies in the region of $P_{\mathrm{bike}}>P_{\mathrm{bc}}$, the flow of bicycles is saturated and reaches the maximal value $q_{\mathrm{bs}}$.

Thus, the phase transition from free flow to the saturation one for both flows is observed in this proposed CA model. The flow rate of motor vehicles or bicycles relies on not only its own inflow rate, but also its counterpart one. Moreover, the mixture of motor vehicles and bicycles near the bus stops results in the drop of saturated flows. The larger the interaction between two flows is, the more the value of saturated flows drops.

Because bus stops of Type I and Type II share the same form with the only difference being in physical segregation setting, the traffic characteristics in the flow of motor vehicles and bicycles of Type II are similar to those of Type I, as is shown in Figures 4 and 5. In the condition that either there is no bicycles on the road $\left(P_{\text {bike }}=0\right)$ or the inflow rate 


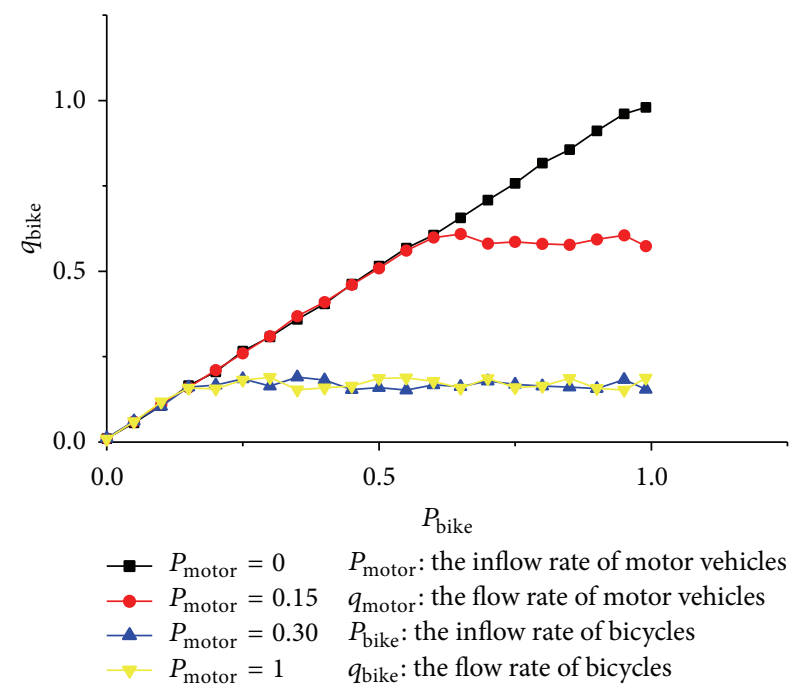

(a)

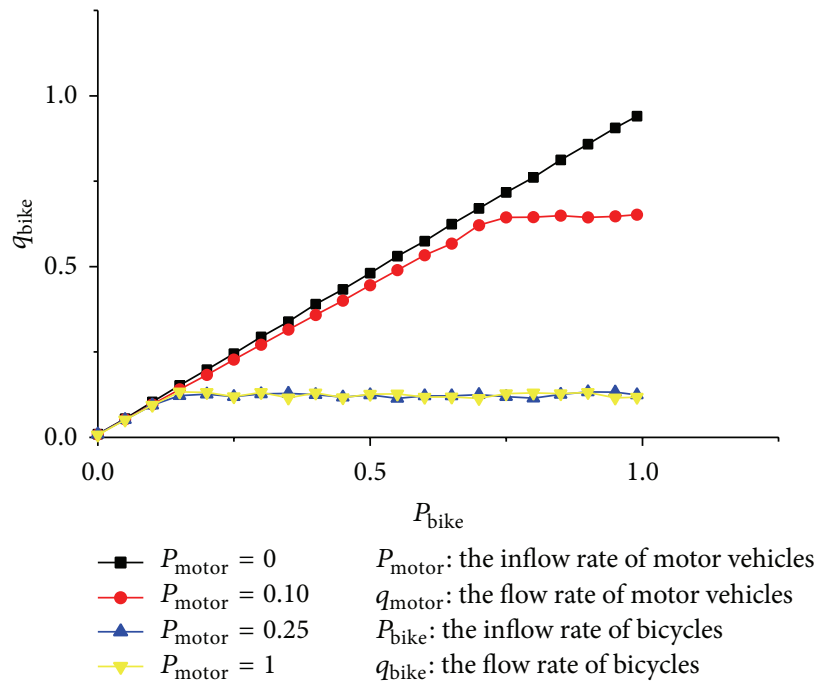

(c)

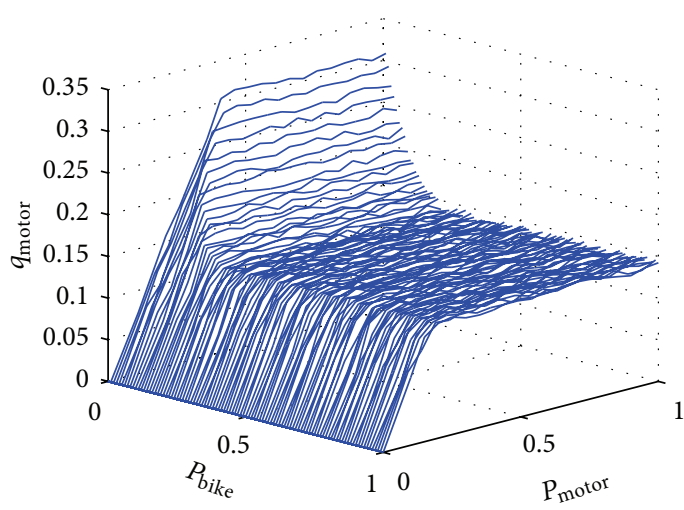

$P_{\text {motor }}:$ the inflow rate of motor vehicles $q_{\text {motor }}$ : the flow rate of motor vehicles $P_{\text {bike }}$ : the inflow rate of bicycles $q_{\text {bike }}$ : the flow rate of bicycles

(b)

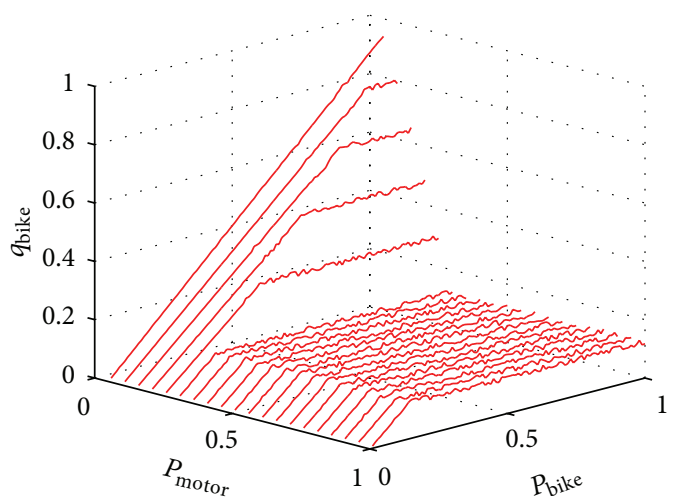

$P_{\text {motor }}$ : the inflow rate of motor vehicles $q_{\text {motor }}$ : the flow rate of motor vehicles $P_{\text {bike }}$ : the inflow rate of bicycles $q_{\text {bike }}:$ the flow rate of bicycles

(d)

Figure 5: The simulation results of Type II bus stops.

of bicycles is maximal $\left(P_{\text {bike }}=1\right)$, the saturated flow value of motor vehicles $\left(q_{\mathrm{ms}}\right)$ is basically the same in both Type I and Type II, which is 0.31 and 0.14 , respectively. However, since bicyclists, if possible, would like to overtake buses from the motor vehicle lane in Type I, the motor vehicle flow is saturated when the inflow rate of bicycles $\left(P_{\text {bike }}\right)$ is equal to 0.28 , the corresponding value of which is 0.22 in Type II, which is shown in Figures 4(a) and 5(a). Besides, as is shown in Figures 4(c) and 5(c), when the bicycle flow is saturated, the inflow rate of motor vehicles $\left(P_{\text {motor }}\right)$ is equal to 0.3 in Type I and in Type II it is 0.25 . This result indicates that the traffic system of Type I bus stop can accommodate more motor vehicles or bicycles when the mixed traffic flow is saturated. However, this increase of traffic volume is at the cost of traffic safety because the risk of accidents increases if bicycles move on motor vehicle lane.

Figure 6 shows the simulation results of bus bay stops of Type III. Because the bicycle lane is physically separated from the motor lane, there is no direct-conflict between motor vehicles and bicycles. Therefore, the flow rate of motor vehicles $\left(q_{\text {motor }}\right)$ is not affected by the inflow rate of bicycles $\left(P_{\text {bike }}\right)$, as is shown in Figure 6(a). For bicycles, stopped buses do not occupy bicycle lane anymore and it makes the saturation flow of bicycles $q_{\mathrm{bs}}$ much higher than that in Type I and Type II. However, since the bus bay stop occupies part of the bicycle lane, the decrease in the width of bicycle lane near bus stop may form a bottleneck in this area. Therefore, the flow rate of bicycles $\left(q_{\text {bike }}\right)$ in Type III is less than that in Type I and Type II when the inflow rate of motor vehicles $\left(P_{\text {motor }}\right)$ is at a lower level.

4.3. Total Capacity of the System. In this section, passenger transport capacity which is defined as the total passengers carried by both motor vehicles and bicycles is introduced. In reality, traffic engineers prefer knowing the total capacity of the system than knowing the flow rate of a certain traffic 


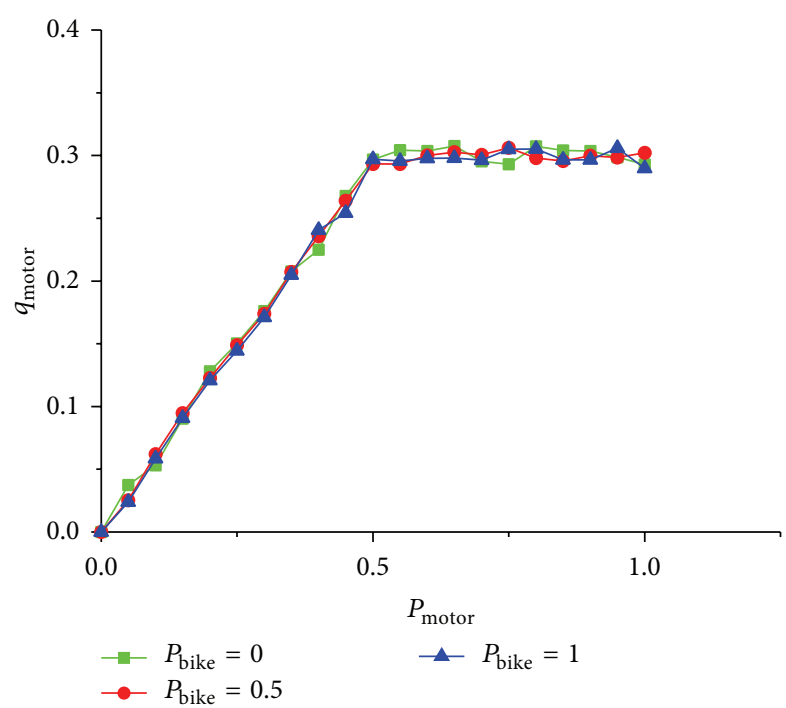

(a)

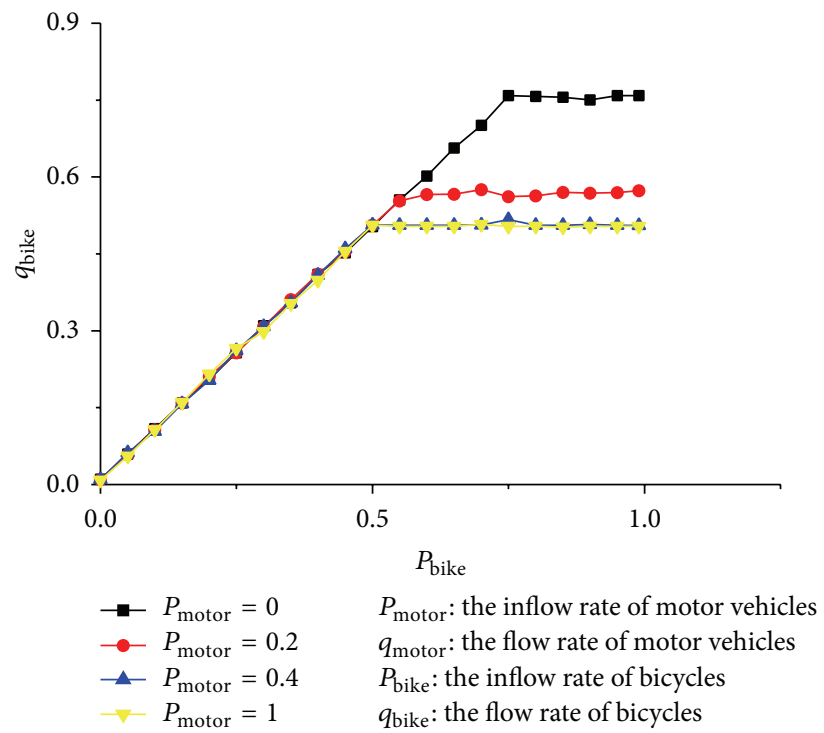

(c)

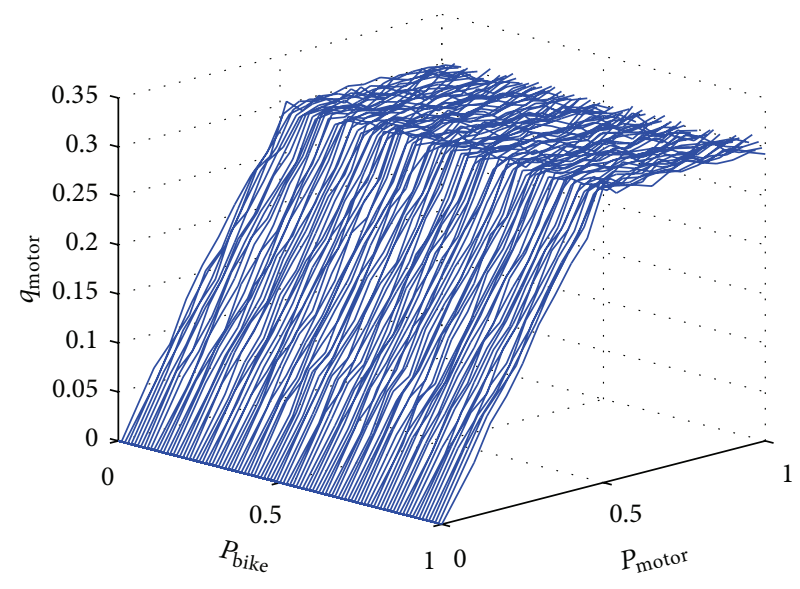

(b)

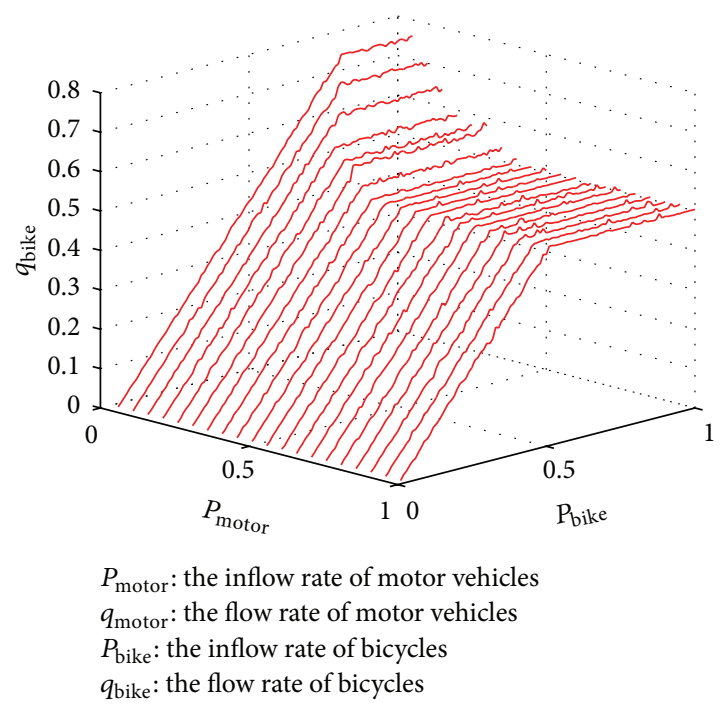

(d)

FIGURE 6: The simulation results of Type III bus stops.

mode before making a decision or evaluating the traffic system. Suggestions on bus stop selection are provided based on this value.

Passenger transport capacity $C_{a}$ of the mixed traffic system is defined as follows:

$$
C_{a}=q_{\mathrm{bus}} \times C_{\mathrm{bus}}+q_{\mathrm{car}} \times C_{\mathrm{car}}+q_{\mathrm{bike}} \times C_{\mathrm{bike}} \times M,
$$

where $C_{a}$ denotes the maximum number of passengers that can be carried by vehicles in the mixed traffic system each time step, $q$ (note that $q_{\text {bike }}$ is defined as the average number of passing bicycles divided by $M$ ) is the flow rate, and $C$ denotes the maximum number of passengers a vehicle could carry. Variables with subscripts bus, car, and bike denote those of buses, cars, and bicycles. In the simulation, we set $C_{\text {bus }}=40$,
$C_{\text {car }}=2$, and $C_{\text {bike }}=1$ according to the average results of our field investigation.

Substituting $P_{m}=0.15$ and $M=4$ into (6), we have

$$
C_{a}=8 \times q_{\text {motor }}+4 \times q_{\text {bike }} .
$$

Figure 7 shows the relationship between $C_{a}, P_{\text {motor }}$, and $P_{\text {bike }}$.

(i) In the region where both the inflow rate of motor vehicles and the inflow rate of bicycles are low $\left(P_{\text {motor }}<0.25\right.$ and $\left.P_{\text {bike }}<0.25\right), C_{a}$ of all the three types is nearly the same and increases with the augmentation of $P_{\text {motor }}$ and $P_{\text {bike }}$. It indicates that both motor vehicles and bicycles are in free flow and any kind of bus stop is acceptable in this region. However, 


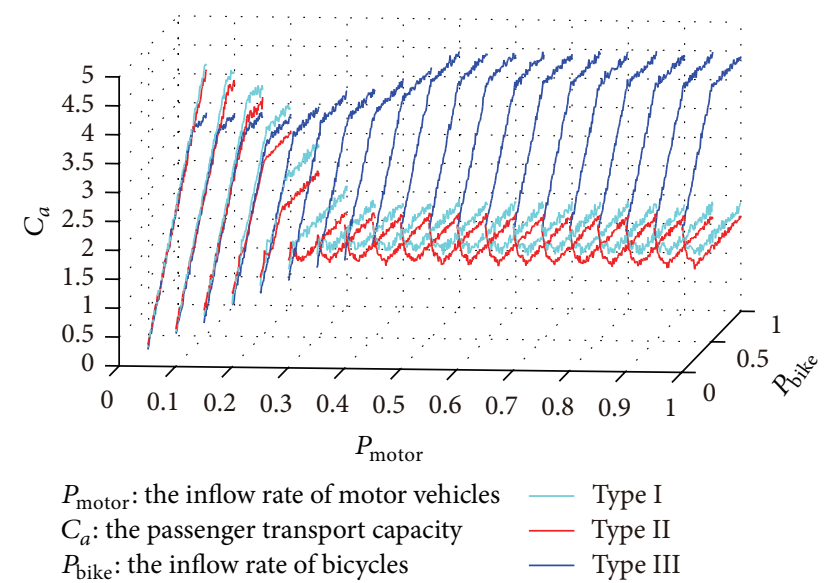

Figure 7: Passenger transport capacity $C_{a}$ versus the inflow rates $P_{\text {motor }}$ and $P_{\text {bike }}$ at three types of bus stops.

considering the traffic security and investment, Type II bus stop is more appropriate.

(ii) In the region where $P_{\text {bike }}$ increases gradually but $P_{\text {motor }}$ remains a small value $\left(P_{\text {motor }}<0.15\right.$ and $0.25<$ $\left.P_{\text {bike }}<1\right), C_{a}$ of Type I is larger than Type II, and Type III is the smallest. The results appear to be reasonable since bicyclists in Type I are able to overtake the buses from the left side when the flow rate of motor vehicles is small, thus resulting in a higher flow rate of bicycles which leads to a larger $C_{a}$. However, since bus bay stops occupy part of bicycle lanes in Type III, the smaller flow rate of bicycles caused by the narrowed lane leads to the smallest $C_{a}$ in this situation. Therefore, when the motor vehicle flow is low and bicycle flow is high, Type III bus stops are not recommended.

(iii) In the region where $0.15<P_{\text {motor }}<0.25$ and $P_{\text {bike }}>$ 0.25 , with the increase of $P_{\text {motor }}$, the maximal $C_{a}$ of Type III is still growing gradually, which becomes higher than that of Type I and Type II. On the contrary, the maximal $C_{a}$ of Type I and Type II decreases with the increase of $P_{\text {motor }}$. It is interesting to note that the decline of $C_{a}$ with the increase of $P_{\text {bike }}$ is more significant in Type II than in Type I. The reason is that, in this region, more and more bicycles are blocked by the increasing number of buses and cars in Type II. In Type I, however, the drop of flow rate of bicycles on bicycle lane is compensated by the passing bicycles on motor vehicle lane.

(iv) In the region where $0.5<P_{\text {motor }}<1$ and $P_{\text {bike }}<0.25$, $C_{a}$ increases with the augmentation of $P_{\text {bike }}$ in Type III. However, $C_{a}$ decreases to the minimum with the increase of $P_{\text {bike }}$ in Type I and Type II.

(v) In the region where $0.5<P_{\text {motor }}<1$ and $0.25<$ $P_{\text {bike }}<1$, it is obvious that $C_{a}$ of all three types of system remains constant and does not change with $P_{\text {motor }}$ and $P_{\text {bike }}$ anymore, which means the flow rate on motor vehicle lanes and bicycle lanes is saturated.
In this region, Type III bus stops are more appropriate since $C_{a}$ of this type is the largest.

\section{Conclusions and Discussions}

In this study, a CA model is proposed to simulate the mixed traffic flow near three typical types of bus stops which are common on secondary roads in China. The NaSch model for motor vehicles and the improved BCA model for bicycles are combined using special lane-changing rules in this model. The flow rate of both motor vehicles and bicycles as well as the passenger transport capacity of the traffic system under various traffic compositions is calculated in order to evaluate three types of bus stops. The phase transition from free flow to the saturation one at the critical point for both two flows is observed. For Type I and Type II bus stops, the inflow rate of both motor vehicles and bicycles can affect the flow rate of the mixed traffic system near bus stops. Besides, the larger the interaction between two flows is, the more the value of saturated flows drops. However, such effect is not apparent in Type III because there is no direct-conflict between motor vehicles and bicycles in this condition.

Based on the simulation results, it can be concluded that curbside bus stops are more suitable than bus bay stops when the flow rate of motor vehicles is relatively small. In this situation, the traffic capacity of bus bay stops is less than that of curbside stops, which is mainly caused by the narrowed bicycle lanes when constructing the bay-style stops. When the flow rate of motor vehicles near bus stops is relatively large, serious conflicts among buses, cars, and bicycles occur, which forms a transport bottleneck near curbside stops. In this situation, bus bay stops should be applied due to their abilities to reduce conflicts of mixed traffic flow.

In future studies, several aspects can be included in the model to solve more practical problems in reality, for example, how to consider differences among various types of vehicles, how to analyze the relation between flow and density of bicycles near bus stops, and how to take the influence of driving psychology into account near bus stops. We are planning to deal with these issues in our future work.

\section{Conflict of Interests}

The authors declare that there is no conflict of interests regarding the publication of this paper.

\section{Acknowledgments}

This research is funded by the National Key Basic Research Program of China (no. 2012CB725402) and the Fundamental Research Funds for the Central Universities (no. KYLX_0171).

\section{References}

[1] R. Z. Koshy and V. T. Arasan, "Influence of bus stops on flow characteristics of mixed traffic," Journal of Transportation Engineering, vol. 131, no. 8, pp. 640-643, 2005. 
[2] Z. Li, W. Wang, C. Yang, and G. Jiang, "Exploring the causal relationship between bicycle choice and trip chain pattern," Transport Policy, vol. 29, pp. 170-177, 2013.

[3] J. Vasic and H. J. Ruskin, "Agent-based space-time discrete simulation of urban traffic including bicycles," Procedia Computer Science, vol. 10, pp. 860-865, 2012.

[4] Y. Tang, H. X. Pan, and Q. Y. Lu, "The evolution and lessons from China Mainland Bike-sharing systems," in Proceedings of the 92nd Annual Meeting of the Transportation Research Board, Washington, DC, USA, January 2013.

[5] D. E. Wolf, M. Schreckenberg, and A. Bachem, Traffic and Granular Flow, World Scientific, Singapore, 1996.

[6] D. Helbing and M. Treiber, "Numerical simulation of macroscopic traffic equations," Computing in Science and Engineering, vol. 1, no. 5, pp. 89-99, 1999.

[7] I. Prigogine and R. Herman, Kinetic Theory of Vehicular Traffic, American Elsevier, New York, NY, USA, 1971.

[8] D. Helbing and M. Treiber, "Gas-kinetic-based traffic model explaining observed hysteretic phase transition," Physical Review Letters, vol. 81, no. 14, pp. 3042-3045, 1998.

[9] D. Ngoduy, "Application of gas-kinetic theory to modelling mixed traffic of manual and ACC vehicles," Transportmetrica, vol. 8, no. 1, pp. 43-60, 2012.

[10] L.-D. Zhang, W.-X. Zhu, and J.-I. Liu, "Proportional-differential effects in traffic car-following model system," Physica A: Statistical Mechanics and its Applications, vol. 406, pp. 89-99, 2014.

[11] Y. Li, H. Zhu, M. Cen, R. Li, and D. Sun, "On the stability analysis of microscopic traffic car-following model: a case study," Nonlinear Dynamics, vol. 74, no. 1-2, pp. 335-343, 2013.

[12] J. Kim and H. S. Mahmassani, "Correlated parameters in driving behavior models," Transportation Research Record, vol. 2249, pp. 62-77, 2011.

[13] D. E. Wolf, "Cellular automata for traffic simulations," Physica A: Statistical Mechanics and its Applications, vol. 263, no. 1-4, pp. 438-451, 1999.

[14] D. Chowdhury, L. Santen, and A. Schadschneider, "Statistical physics of vehicular traffic and some related systems," Physics Reports, vol. 329, no. 4-6, pp. 199-329, 2000.

[15] K. Nagel and M. Schreckenberg, "A cellular automaton model for freeway traffic," Journal de Physique I, vol. 2, no. 12, pp. 22212229, 1992.

[16] S. C. Benjamin, N. F. Johnson, and P. M. Hui, "Cellular automata models of traffic flow along a highway containing a junction," Journal of Physics A: Mathematical and General, vol. 29, no. 12, pp. 3119-3127, 1996.

[17] R. Barlovic, L. Santen, A. Schadschneider, and M. Schreckenberg, "Metastable states in cellular automata for traffic flow," The European Physical Journal B-Condensed Matter and Complex Systems, vol. 5, no. 3, pp. 793-800, 1998.

[18] P. Wagner, K. Nagel, and D. E. Wolf, "Realistic multi-lane traffic rules for cellular automata," Physica A: Statistical Mechanics and Its Applications, vol. 234, no. 3-4, pp. 687-698, 1997.

[19] K. Nagel, D. E. Wolf, P. Wagner, and P. Simon, "Two-lane traffic rules for cellular automata: a systematic approach," Physical Review E, vol. 58, no. 2, pp. 1425-1437, 1998.

[20] S. Kukida, J. Tanimoto, and A. Hagishima, "Analysis of the influence of lane changing on traffic-flow dynamics based on the cellular automaton model," International Journal of Modern Physics C, vol. 22, no. 3, pp. 271-281, 2011.

[21] X.-D. Hua, W. Wang, and H. Wang, "A two-lane cellular automaton traffic flow model with the influence of driving psychology," Acta Physica Sinica, vol. 60, no. 8, Article ID 084502, 2011.

[22] B. Jia, X.-G. Li, R. Jiang, and Z.-Y. Gao, "Multi-value cellular automata model for mixed bicycle flow," The European Physical Journal B, vol. 56, no. 3, pp. 247-252, 2007.

[23] X.-F. Yang, W. Mao, and Q. Fu, "Modeling of bicycle flow based on dynamic floor field and cellular automata," Acta Physica Sinica, vol. 62, no. 24, 2013.

[24] Z. Li, W. Wang, P. Liu, J. Bigham, and D. R. Ragland, "Modeling bicycle passing maneuvers on multilane separated bicycle paths," Journal of Transportation Engineering, vol. 139, no. 1, pp. 57-64, 2013.

[25] R. Jiang, B. Jia, and Q.-S. Wu, "Stochastic multi-value cellular automata models for bicycle flow," Journal of Physics A: Mathematical and General, vol. 37, no. 6, pp. 2063-2072, 2004.

[26] J. Vasic and H. J. Ruskin, "Cellular automata simulation of traffic including cars and bicycles," Physica A: Statistical Mechanics and its Applications, vol. 391, no. 8, pp. 2720-2729, 2012.

[27] X.-Q. Zhang, Y. Wang, and Q.-H. Hu, "Research and simulation on cellular automaton model of mixed traffic flow at intersection," Acta Physica Sinica, vol. 63, no. 1, Article ID 010508, 2014.

[28] X.-M. Zhao, B. Jia, Z.-Y. Gao, and R. Jiang, "Traffic interactions between motorized vehicles and nonmotorized vehicles near a bus stop," Journal of Transportation Engineering, vol. 135, no. 11, pp. 894-906, 2009.

[29] D. Zhao, W. Wang, Y. Zheng, Y. Ji, and X. Hu, "Evaluation of interactions between buses and bicycles at stops," Transportation Research Board Annual Meeting 2014 Paper 14-1417, Transportation Research Board of the National Academies, Washington, DC, USA, 2014.

[30] L. Lu, Y. Su, D. Yao, L. Peng, M. Ding, and R. Xu, “The delay of bus near a stop when mixed traffic flow is considered," in Proceedings of the IEEE Intelligent Vehicles Symposium (IV '10), pp. 1104-1109, San Diego, Calif, USA, June 2010. 


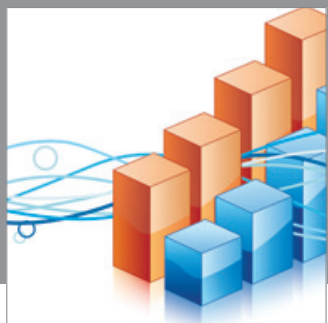

Advances in

Operations Research

mansans

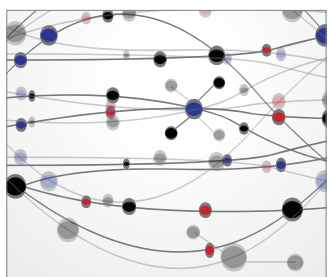

The Scientific World Journal
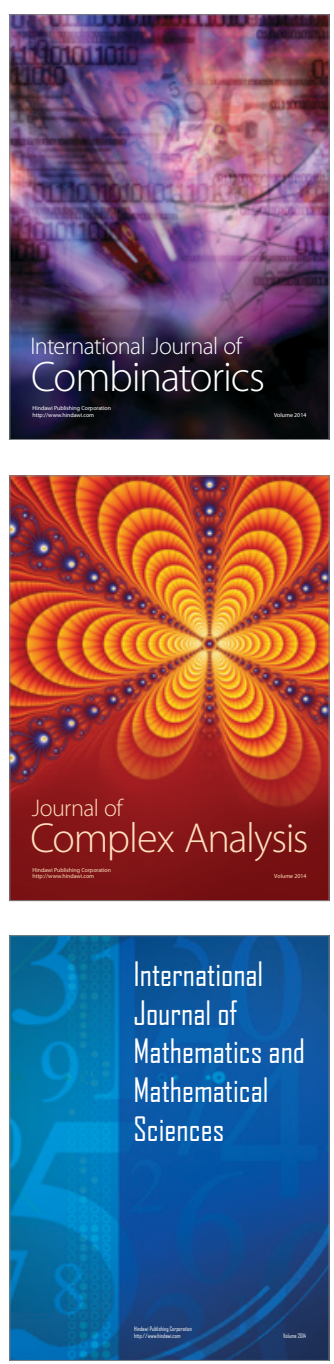
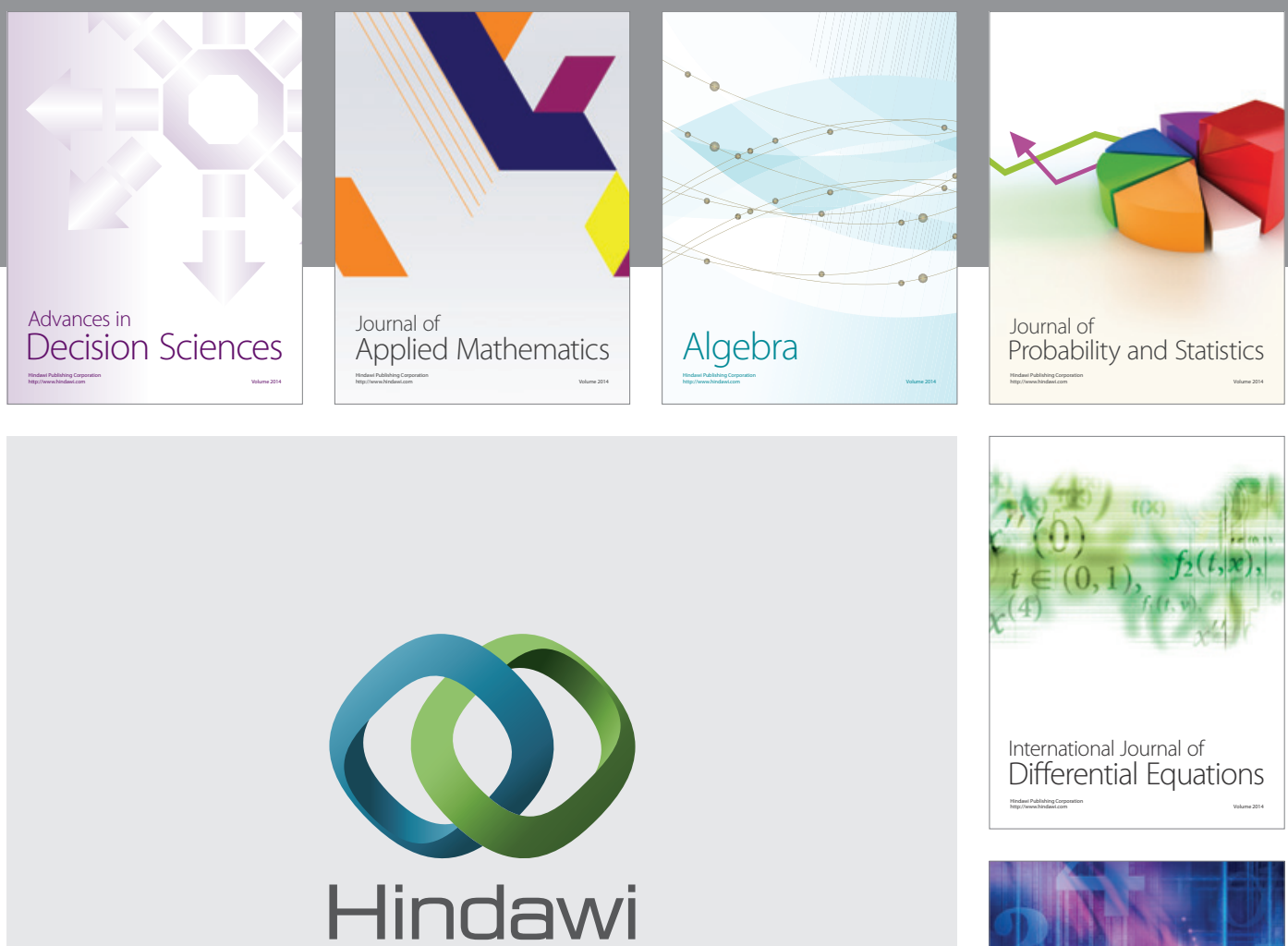

Submit your manuscripts at http://www.hindawi.com
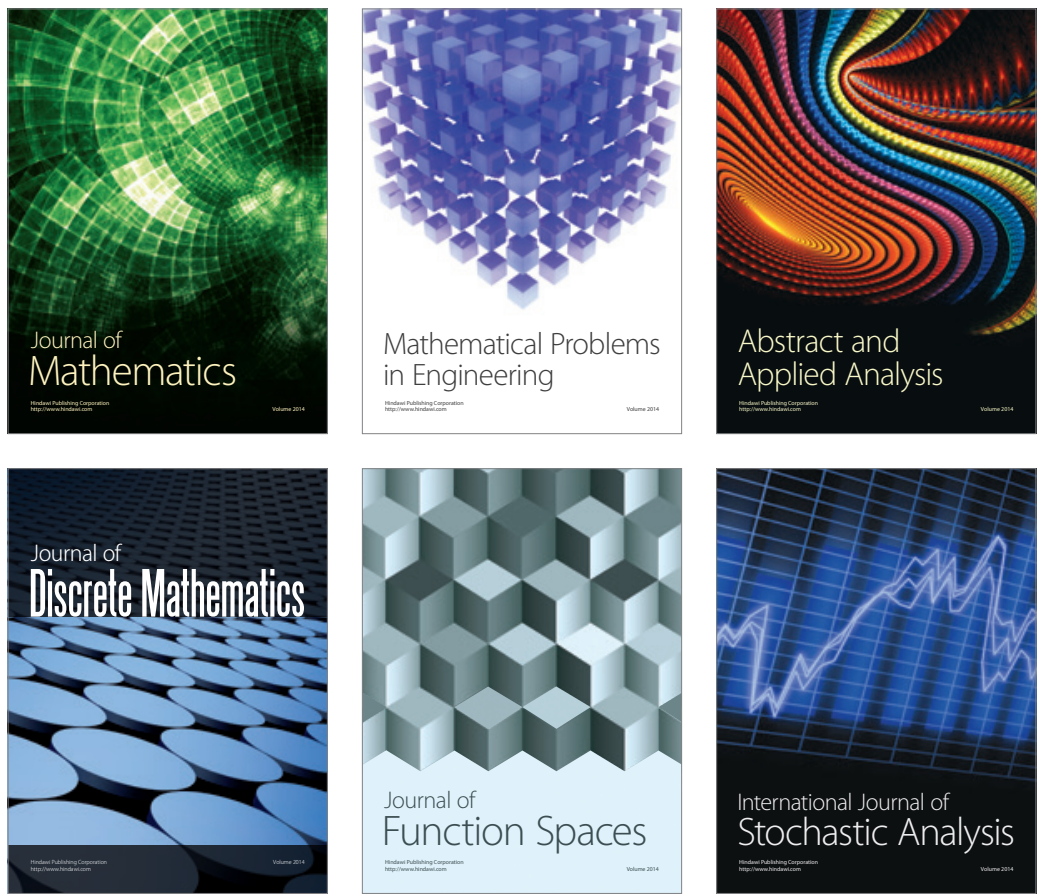

Journal of

Function Spaces

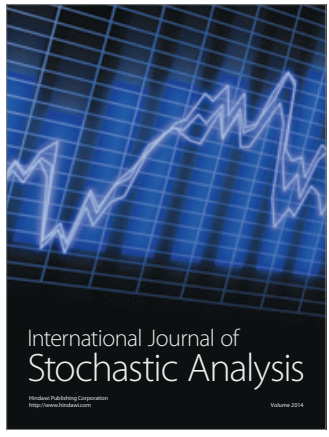

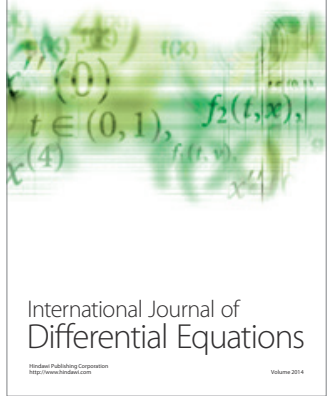
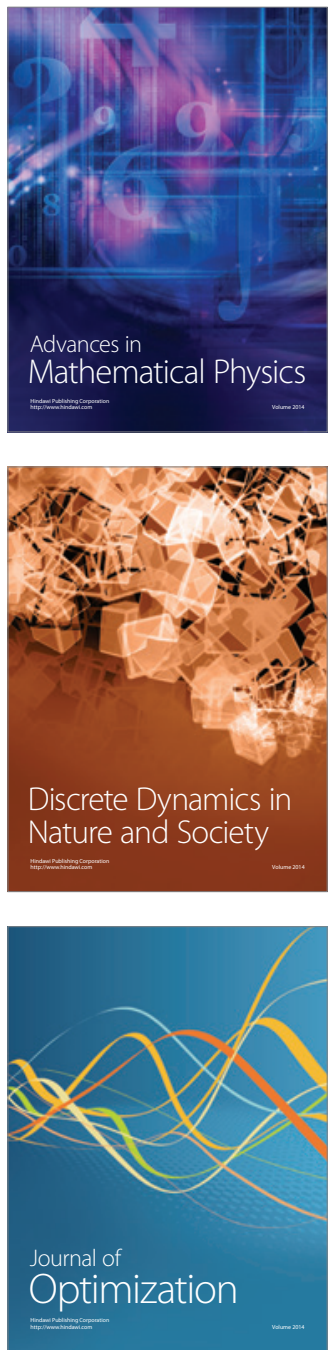